\title{
Optimal flow rate for antegrade cerebral perfusion
}

\author{
Takashi Sasaki, MD, ${ }^{\text {a }}$ Shoichi Tsuda, MD, ${ }^{\text {a }}$ R. Kirk Riemer, PhD, ${ }^{\text {a }}$ Chandra Ramamoorthy, MD,${ }^{\mathrm{b}}$ \\ V. Mohan Reddy, MD, ${ }^{a}$ and Frank L. Hanley, MD ${ }^{\mathrm{a}}$
}

Objective: Antegrade cerebral perfusion is widely used in neonatal heart surgery, yet commonly used flow rates have never been standardized. The objective of this study was to determine the antegrade cerebral perfusion flow rate that most closely matches standard cardiopulmonary bypass conditions.

\begin{abstract}
Methods: Nine neonatal piglets underwent deep hypothermic cardiopulmonary bypass at a total body flow of $100 \mathrm{~mL} / \mathrm{kg} / \mathrm{min}$ (baseline). Antegrade cerebral perfusion was conducted via innominate artery cannulation at perfusion rates of 10,30 , and $50 \mathrm{~mL} / \mathrm{kg} / \mathrm{min}$ in random order. Cerebral blood flow was measured using fluorescent microspheres. Regional oxygen saturation and cerebral oxygen extraction were monitored.
\end{abstract}

\begin{abstract}
Results: Cerebral blood flow was as follows: baseline, $60 \pm 17 \mathrm{~mL} / 100 \mathrm{~g} / \mathrm{min}$; antegrade cerebral perfusion at $50 \mathrm{~mL} / \mathrm{kg} / \mathrm{min}, 56 \pm 17 \mathrm{~mL} / 100 \mathrm{~g} / \mathrm{min}$; antegrade cerebral perfusion at $30 \mathrm{~mL} / \mathrm{kg} / \mathrm{min}, 36 \pm 9 \mathrm{~mL} / 100 \mathrm{~g} / \mathrm{min}$; and antegrade cerebral perfusion at $10 \mathrm{~mL} / \mathrm{kg} / \mathrm{min}, 13 \pm 6 \mathrm{~mL} / 100 \mathrm{~g} / \mathrm{min}$. At an antegrade cerebral perfusion rate of $50 \mathrm{~mL} / \mathrm{kg} / \mathrm{min}$, cerebral blood flow matched baseline $(P=.87)$, as did regional oxygen saturation $(P=.13)$. Antegrade cerebral perfusion at $30 \mathrm{~mL} / \mathrm{kg} / \mathrm{min}$ provided approximately $60 \%$ of baseline cerebral blood flow $(P<.002)$; however, regional oxygen saturation was equal to baseline $(P=.93)$. Antegrade cerebral perfusion at $10 \mathrm{~mL} / \mathrm{kg} / \mathrm{min}$ provided $20 \%$ of baseline cerebral blood flow $(P<.001)$ and a lower regional oxygen saturation than baseline $(P=.011)$. Cerebral oxygen extraction at antegrade cerebral perfusion rates of 30 and $50 \mathrm{~mL} / \mathrm{kg} /$ min was equal to baseline $(P=.53, .48)$ but greater than baseline $(P<.0001)$ at an antegrade cerebral perfusion rate of $10 \mathrm{~mL} / \mathrm{kg} / \mathrm{min}$. The distributions of cerebral blood flow and regional oxygen saturation were equal in each brain hemisphere at all antegrade cerebral perfusion rates.
\end{abstract}

Conclusion: Cerebral blood flow increased with antegrade cerebral perfusion rate. At an antegrade cerebral perfusion rate of $50 \mathrm{~mL} / \mathrm{kg} / \mathrm{min}$, cerebral blood flow was equal to baseline, but regional oxygen saturation and cerebral oxygen extraction trends suggested more oxygenation than baseline. An antegrade cerebral perfusion rate of $30 \mathrm{~mL} / \mathrm{kg} / \mathrm{min}$ provided only $60 \%$ of baseline cerebral blood flow, but cerebral oxygen extraction and regional oxygen saturation were equal to baseline. An antegrade cerebral perfusion rate that closely matches standard cardiopulmonary bypass conditions is between 30 and $50 \mathrm{~mL} / \mathrm{kg} / \mathrm{min}$. (J Thorac Cardiovasc Surg 2010;139:530-5)

Antegrade cerebral perfusion (ACP) was developed as an alternative to deep hypothermic circulatory arrest (DHCA) as a cardiopulmonary bypass (CPB) management strategy for complex arch reconstructions. The question of whether ACP is less morbid than DHCA is controversial. Although this issue will not be addressed in this study, it remains a fact that ACP is widely used in the clinical setting. There are no data documenting how much flow the brain receives during ACP or how ACP brain flow compares with brain flow during many standard CPB conditions. This study addresses the question of how much blood flow is needed during ACP to provide the level of oxygen delivery to the brain

\footnotetext{
From Stanford University, Division of Pediatric Cardiac Surgery, Departments of Cardiothoracic Surgery ${ }^{\mathrm{a}}$ and Anesthesiology, ${ }^{\mathrm{b}}$ Stanford, Calif.

Disclosures: None.

Received for publication July 1, 2009; revisions received Nov 24, 2009; accepted for publication Dec 7, 2009.

Address for reprints: Frank L. Hanley, MD, Stanford University, Department of Cardiothoracic Surgery, 300 Pasteur Drive, Falk Rm CV116C, Stanford, CA 94305-5407 (E-mail: fhanley@stanford.edu).

$0022-5223 / \$ 36.00$

Copyright @ 2010 Published by Elsevier Inc. on behalf of The American Association for Thoracic Surgery

doi:10.1016/j.jtcvs.2009.12.005
}

that is equivalent to that delivered using total-body CPB. Our premise for the study is that because ACP is a widely used bypass strategy for complex arch reconstructions, it is important to understand how ACP flow rates relate to actual cerebral oxygen delivery.

ACP has evolved over the past 15 years. However, the perceived ideal ACP flow rate varies 3 -fold among different centers $(20-63 \mathrm{~mL} / \mathrm{kg} / \mathrm{min})^{1-4}$ and has never been standardized. During neonatal deep hypothermic $\left(18^{\circ} \mathrm{C}-20^{\circ} \mathrm{C}\right) \mathrm{CPB}$, a total body flow rate of $100 \mathrm{~mL} / \mathrm{kg} / \mathrm{min}$ is commonly used in practice as a standard. ${ }^{5}$ The ACP rate that provides cerebral perfusion equal to the standard total body flow rate of $100 \mathrm{~mL} / \mathrm{kg} / \mathrm{min}$ has not been determined.

During ACP, the innominate artery is cannulated, and thus, direct perfusion is isolated to the right cerebral hemisphere and right arm, whereas the left cerebral hemisphere is perfused via the Circle of Willis. The left and right regional blood flow distribution in the brain during ACP is not well documented.

We determined cerebral blood flow (CBF) at a total body flow rate of $100 \mathrm{~mL} / \mathrm{kg} / \mathrm{min}$ and at each of 3 different ACP rates under deep hypothermic $\mathrm{CPB}$ to determine their relation. Regional blood distribution in the brain (right and 

Abbreviations and Acronyms
$\mathrm{ACP}=$ antegrade cerebral perfusion
$\mathrm{CBF}=$ cerebral blood flow
$\mathrm{CPB}=$ cardiopulmonary bypass
$\mathrm{DHCA}=$ deep hypothermic circulatory arrest
NIRS = near-infrared spectroscopy
$\mathrm{rSO} 2=$ regional oxygen saturation

left hemispheres) and cerebral oxygen metabolism were also investigated.

\section{MATERIALS AND METHODS}

All animals received humane care in compliance with the Guide for the Care and Use of Laboratory Animals (www.nap.edu/catalog/5140.html). Neonatal piglets $(\mathrm{n}=9)$, weighing 3.5 to $4.4 \mathrm{~kg}$, underwent induction of anesthesia with intramuscular ketamine $(10 \mathrm{mg} / \mathrm{kg})$ and atropine $(0.04$ $\mathrm{mg} / \mathrm{kg}$ ), and were intubated with a 3-mm cuffed endotracheal tube. Animals were ventilated to normocapnia on $100 \%$ oxygen. Anesthesia was maintained with inhalation of $1 \%$ to $2 \%$ isoflurane. In addition, fentanyl $5 \mu \mathrm{g} / \mathrm{kg}$ was administered before $\mathrm{CPB}$, and muscle relaxation was provided with $0.1 \mathrm{mg} / \mathrm{kg}$ doses of pancuronium bromide. Rectal and nasopharyngeal temperatures were continuously monitored.

Pressure monitoring catheters were placed in the right femoral artery and right subclavian artery, and a central venous line was placed under direct vision through an incision in the left jugular vein.

\section{Cardiopulmonary Bypass Circuit and Experimental Protocol}

The animals were placed supine, a midline sternotomy was performed, the heart and great vessels were exposed, and heparin (300 IU/kg) was administered. The innominate artery was cannulated $(6 \mathrm{~F}$ or $8 \mathrm{~F}$ arterial BioMedicus; Medtronic, Minneapolis, Minn), a 14F single-stage venous cannula (Edwards Lifesciences, Irvine, Calif) was inserted into the right atrial appendage, and CPB was initiated.

The CPB circuit consisted of a roller pump (COBE Cardiovascular Inc, Arvada, Colo), a membrane oxygenator (Dideco Kids D100, Sorin Group USA, Arvada, Colo), an arterial filter (Dideco Kids D130, Sorin Group USA), and quarter-inch inside diameter tubing. The circuit was primed with donor pig blood mixed with crystalloid prime solution (Normosol R; Abbott Laboratories, North Chicago, Ill) to maintain hematocrit no less than $30 \%$. In addition, heparin $1000 \mathrm{IU}$ and sodium bicarbonate $(5 \mathrm{mEq})$ were added to the priming solution.

$\mathrm{CPB}$ was initiated with the aid of vacuum-assisted venous drainage. Additional fentanyl $(10 \mu \mathrm{g} / \mathrm{kg})$ was administered to the piglet, and $1 \%$ to $2 \%$ isoflurane was continued on the pump. Core cooling was commenced at a pump flow of $200 \mathrm{~mL} / \mathrm{kg} / \mathrm{min}$ using $\mathrm{pH}$-stat arterial blood gas management, and hematocrit was maintained between $25 \%$ and $30 \%$. Phentolamine was administered during the cooling process at $0.2 \mathrm{mg} / \mathrm{kg}$ to facilitate an even and effective cooling process that was conducted for a minimum of 30 minutes to ensure uniform cooling of the central nervous system. Continuous blood gas monitoring during cooling was performed with Terumo CDI (Terumo CDI 500; Terumo Corporation, Tokyo, Japan). Inflow temperature was meticulously controlled and kept no lower than $10^{\circ} \mathrm{C}$ below the measured nasopharyngeal temperature. Once nasopharyngeal temperature reached $18^{\circ} \mathrm{C}$, total body perfusion rate was reduced to $100 \mathrm{~mL} / \mathrm{kg} / \mathrm{min}$ for 15 minutes, the aorta was clamped, and cold cardioplegia (Plegisol; Abbott Laboratories) was administered via the aortic root. CBF was then measured at a total body flow of $100 \mathrm{~mL} / \mathrm{kg} / \mathrm{min}$ using $15-\mu \mathrm{m}$ microspheres injected into the pump outflow line, and the value obtained under this standard $\mathrm{CPB}$ condition was chosen as the reference baseline $\mathrm{CBF}$ for comparison with ACP.

The proximal innominate artery, left carotid artery, and left subclavian artery were clamped, and ACP was initiated at each of 3 perfusion rates $(10,30$, or $50 \mathrm{~mL} / \mathrm{kg} / \mathrm{min})$ in random order. Each perfusion rate was continued for 15 minutes before switching to the next flow rate, and microspheres were injected at each rate to determine CBF. The piglets were then euthanized, the brains were dissected, and microsphere-derived $\mathrm{CBF}$ was determined as milliliters of blood flow/100 g tissue/min. CBF at each of the $\mathrm{ACP}$ rates was then compared with the baseline $\mathrm{CBF}$ at total body perfusion $(100 \mathrm{~mL} / \mathrm{kg} / \mathrm{min})$. Bihemispheric regional cranial oxygen saturations ${ }^{6}$ (rSO2) were continuously monitored using bilateral cranial near-infrared spectroscopy (NIRS) sensors (INVOS model 5100C cerebral oximeter with SPFP pediatric sensors; Somantics Corporation, Troy, MI) during the procedure. Blood samples from the right subclavian artery and left jugular vein were simultaneously withdrawn to calculate cerebral oxygen extraction at baseline and under each ACP condition.

\section{Microsphere Assay}

All microsphere procedures were performed with reference to the classic review by Heymann ${ }^{7}$ and protocols from the Fluorescent Microsphere Resource Center (University of Washington, Division of Pulmonary and Critical Care Medicine, Seattle, Wash; http://fmrc.pulmcc.washington. edu/Documents.shtml). In each experiment, 4 different colors of $15-\mu \mathrm{m}$ diameter polystyrene microspheres (FluoSpheres; Molecular Probes, Eugene, Ore) were used for the injections. Each color of microsphere was supplied as an aqueous suspension at a concentration of $1.0 \times 10^{6}$ microspheres per milliliter. Before use, the microspheres were resuspended by sonication; $0.2 \mathrm{~mL}$ of the suspension (200,000 beads) was withdrawn from the stock vial, added directly into $6 \mathrm{~mL}$ of blood from the bypass circuit, mixed gently by several inversions, and then injected into the pump outflow line.

After euthanization, the brain was removed and hemispheres were divided at the middle. Each hemisphere was subdivided to cortex, medulla (hippocampus and brain stem), and cerebellar subregions.

The tissue subregions were further dissected into smaller portions as needed, weighed and transferred to $50 \mathrm{~mL}$ polyethylene tubes, and digested in $4 \mathrm{~mol} / \mathrm{L}$ ethanolic potassium hydroxide ( $224.4 \mathrm{~g}$ potassium hydroxide per liter of $100 \%$ ethanol) containing a final concentration of $0.5 \%$ Tween 80 at a maximum ratio of $5 \mathrm{~g}$ of tissue per $40 \mathrm{~mL}$ solvent. To calculate recovery rate during the microsphere extraction procedure, 4000 microspheres $(200$ $\mu \mathrm{L}$ of a 20,000 sphere/mL suspension in $0.25 \%$ Tween 80 ) of an additional color microsphere was added to each weighed tissue aliquot as an internal standard. Recovery rate was calculated from each sample, ranging from $79 \% \pm 12 \%$ to $91 \% \pm 11 \%$, with a grand mean calculated as $85 \% \pm$ $19 \%$ recovery $(\mathrm{n}=322$ determinations, including other studies conducted in our laboratory). The $85 \%$ recovery value was used to correct the measured concentration of microspheres in each sample.

To enhance digestion, the tubes were placed in a $50^{\circ} \mathrm{C}$ water bath for 48 hours and manually shaken after 24 hours. The digested samples were centrifuged ( 30 minutes at $2000 \mathrm{~g}$ ), and the supernatant was carefully removed. The pellet, containing microspheres and some debris, was completely resuspended in $1 \%$ Triton $\mathrm{X}-100$ by vortexing and then centrifuged again (30 minutes at $2000 \mathrm{~g}$ ). A final rinsing step was performed with phosphate buffer $(0.01 \mathrm{~mol} / \mathrm{L}, \mathrm{pH} 7.4)$. After the final centrifugation, the supernatant was carefully removed while preventing disturbance of the pellet. Finally, $3 \mathrm{~mL}$ of 2-ethoxyethyl acetate was added to the pellet to extract the fluorescent dye from the microspheres. Tubes were then vortexed and allowed to stand for approximately 24 hours, vortexed again, and centrifuged (30 minutes at $2000 \mathrm{~g}$ ), leaving a clear solvent in which fluorescence was determined.

Fluorescence was determined with a SpectraMax M5e plate reader (Molecular Devices, Sunnyvale, Calif) with an excitation wavelength range 
from 350 to $636 \mathrm{~nm}$ and an emission wavelength range from 428 to $680 \mathrm{~nm}$. The concentration of microspheres (microspheres/milliliter of solvent) was calculated from standard curves generated from serial dilutions of known concentrations of each color microsphere dissolved in 2-ethoxyethyl acetate.

\section{Cerebral Blood Flow and Cerebral Perfusion \\ Pressure}

Injected microspheres are distributed to body tissues in proportion to the blood flow to each tissue and trapped in the capillary bed. Thus, the distribution fraction is calculated as follows: distribution fraction $=$ microspheres in the tissue/total microspheres injected.

If the cardiac output is known, a quantitative measure of blood flow $\left(\mathrm{Q}_{\text {Tissue }}, \mathrm{mL} / \mathrm{min}\right)$ can be obtained: $\mathrm{Q}_{\text {Tissue }}=$ cardiac output $\times$ distribution fraction.

Cardiac output can be considered equal to pump flow rate during $\mathrm{CPB}$, and $\mathrm{CBF}$ was calculated with the following formula: $\mathrm{CBF}(\mathrm{mL} / 100 \mathrm{~g} / \mathrm{min})=$ pump flow rate $\times$ microsphere counts in the brain/200,000.

Cerebral perfusion pressure was calculated as (mean subclavian arterial pressure - jugular venous pressure).

\section{Cerebral Metabolism}

Right subclavian arterial and left jugular venous blood samples were obtained simultaneously for calculation of cerebral oxygen extraction (arteriovenous oxygen content difference): $\%$ cerebral oxygen extraction $=(\mathrm{CaO} 2$ $-\mathrm{CvO} 2) / \mathrm{CaO} 2 \times 100$, where $\mathrm{CaO} 2$ was the arterial oxygen content and $\mathrm{CvO} 2$ was the venous oxygen content.

Arterial and venous blood $\mathrm{pH}$, oxygen tension, carbon dioxide tension, hematocrit, and oxygen saturation, as well as glucose and lactate, were measured with using an ABL 825 analyzer (Radiometer America, Westlake, $\mathrm{OH})$.

\section{Statistical Analysis}

Data are given as mean \pm standard deviation. Statistical analysis was performed with JMP statistical software version 6 (JMP USA, SAS Inc, Cary, NC). Blood flow values in brain tissue were first compared among brain subregions (cortex, medulla, and cerebellum) at each flow rate. Next, the flow data were aggregated by summation into right and left hemisphere flows and compared as right and left hemisphere flows, which were found to be statistically equal. The reported $\mathrm{CBF}$ is therefore a global value representing the sum of flow values for a total of 6 subregions (3/hemisphere). $\mathrm{CBF}, \mathrm{rSO} 2$, and cerebral extraction of oxygen at different ACP flow rates were compared using 1-way analysis of variance for multiple comparisons followed by Dunnett's post hoc test. Right and left side blood flow and rSO2 were compared using paired $t$ test corrected for multiple comparisons.

\section{RESULTS}

\section{Blood Flow to the Brain}

$\mathrm{CBF}$ was found to change with $\mathrm{ACP}$ rate (Figure 1). $\mathrm{CBF}$ rates at ACP-10 $(13 \pm 6 \mathrm{~mL} / 100 / \mathrm{min}, P<.001, \mathrm{n}=9)$ and ACP-30 $(36 \pm 9 \mathrm{~mL} / 100 \mathrm{~g} / \mathrm{min}, P<.002, \mathrm{n}=9)$ were lower than that of baseline $(60 \pm 17 \mathrm{~mL} / \mathrm{kg} / \mathrm{min}, \mathrm{n}=8) . \mathrm{CBF}$ at an $\mathrm{ACP}$ rate of $50 \mathrm{~mL} / \mathrm{kg} / \mathrm{min}$ matched the $\mathrm{CBF}$ achieved during baseline $(56 \pm 17 \mathrm{~mL} / 100 \mathrm{~g} / \mathrm{min}, P=.87, \mathrm{n}=9)$. The rate of increase in $\mathrm{CBF}$ was linearly dependent on ACP flow rate $\left(\mathrm{y}=1.076 \mathrm{x}+2.427, \mathrm{R}^{2}=0.7221, P<.001, \mathrm{n}=27\right)$ (Figure 2, $A$ ) and cerebral perfusion pressure $(\mathrm{y}=0.671 \mathrm{x}$ $+2.502, \mathrm{R}^{2}=0.6353, P<.001, \mathrm{n}=27$ ) (Figure 2, B). $\mathrm{CBF}$ as percent of cardiac output was also determined (Fig-

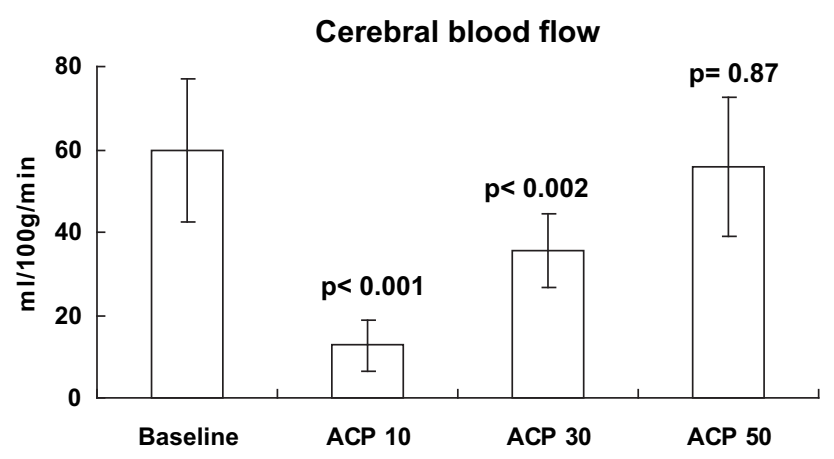

FIGURE 1. CBF during ACP. CBF at baseline (total body flow of $100 \mathrm{~mL} /$ $\mathrm{kg} / \mathrm{min}$ ) and each ACP flow rate was measured. $\mathrm{CBF}$ at ACP rate of 10 and $30 \mathrm{~mL} / \mathrm{kg} / \mathrm{min}$ was lower than that of baseline $(P<.001, P<.002$, $\mathrm{n}=9,9$ vs baseline of $60 \pm 17, \mathrm{n}=8$ ). CBF at an ACP rate of $50 \mathrm{~mL} / \mathrm{kg} / \mathrm{min}$ $(56 \pm 17 \mathrm{~mL} / 100 \mathrm{~g} / \mathrm{min}, P=.87, \mathrm{n}=9)$ matched the $\mathrm{CBF}$ achieved during baseline. ACP, Antegrade cerebral perfusion.

ure 2,C). At baseline, fractional flow to the brain was $6.5 \%$ $\pm 1.8 \%(\mathrm{n}=8)$. During ACP, fractional flow to the brain was approximately 2 times that of baseline at all ACP flow rates $(\mathrm{ACP}-10,14 \% \pm 6 \%, P=.006, \mathrm{n}=9$; ACP-30, $13 \% \pm 3 \%, P=.02, \mathrm{n}=9 ;$ ACP-50, $13 \% \pm 5 \% ; P=.01$, $\mathrm{n}=9$ ).

\section{Cerebral Oxygen Extraction}

We computed cerebral oxygen extraction at baseline and different ACP flow rates (Figure 3). Percent oxygen extraction by the brain was approximately 3 times higher at an ACP rate of $10 \mathrm{~mL} / \mathrm{kg} / \mathrm{min}$ than that of baseline $(37 \pm 14$ vs $13 \pm 8, \mathrm{n}=8,8 ; P<.0001)$. However, at an ACP rate of 30 or $50 \mathrm{~mL} / \mathrm{kg} / \mathrm{min}$, it was not different from baseline $(18 \pm 9, P=.53, \mathrm{n}=9 ; 8 \pm 3, P=.48, \mathrm{n}=9)$, although there was a trend for cerebral oxygen extraction to be lower at ACP-50.

\section{Regional Oxygen Saturation}

rSO2 determined by NIRS was measured for each blood flow rate. The average rSO2 of the right and left hemispheres was computed for each flow rate in each experiment, and these mean cerebral $\mathrm{rSO} 2$ values were used for statistical analyses (Figure 4). Compared with baseline (79 \pm 13 , n $=8), \mathrm{rSO} 2$ was lower at an ACP rate of $10 \mathrm{~mL} / \mathrm{kg} / \mathrm{min}$ $(62 \pm 15, P=.011, \mathrm{n}=8)$ and equal at $\mathrm{ACP}$ rates of 30 $\mathrm{mL} / \mathrm{kg} / \mathrm{min}(82 \pm 9, P=.93, \mathrm{n}=9)$ and $50 \mathrm{~mL} / \mathrm{kg} / \mathrm{min}$ $(90 \pm 4, P=.13, \mathrm{n}=9)$.

\section{Distribution of Blood Flow and Oxygen to Right and Left Cerebral Hemispheres}

We compared the distribution of blood flow and oxygen delivery between right and left brain hemispheres. At baseline total body flow and each of the ACP flow rates, the blood flow rates to the left and right hemispheres were equal (Figure 5, $A$ : baseline, $P=.75$; ACP-10, $P=.67$; ACP-30, 

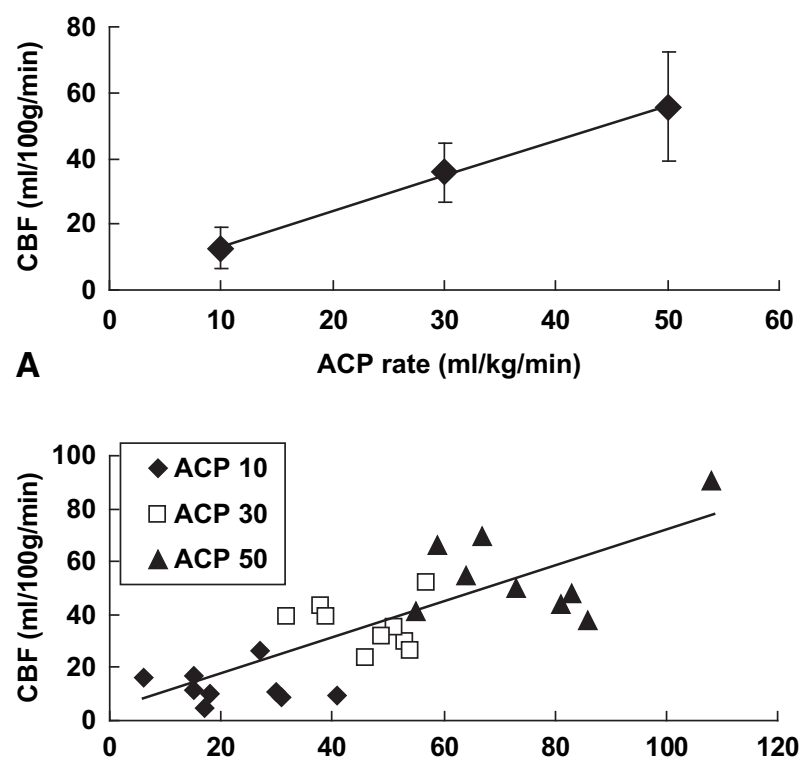

B Cerebral Perfusion Pressure $(\mathrm{mmHg})$

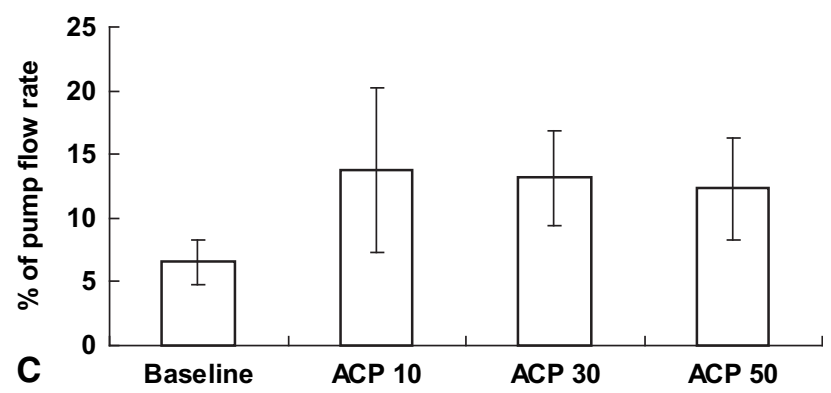

FIGURE 2. A, Relation between $\mathrm{CBF}$ and $\mathrm{ACP}$ flow rates. The rate of increase in $\mathrm{CBF}$ was linearly dependent on ACP flow rate $(\mathrm{y}=1.076 \mathrm{x}+$ $\left.2.427, \mathrm{R}^{2}=0.7221, P<.001, \mathrm{n}=27\right)$. B, Relation between $\mathrm{CBF}$ and perfusion pressure. The rate of increase in $\mathrm{CBF}$ was linearly dependent on cerebral perfusion pressure $\left(\mathrm{y}=0.671 \mathrm{x}+2.502, \mathrm{R}^{2}=0.6353, P<.001, \mathrm{n}=\right.$ 27). $\mathrm{C}, \mathrm{CBF}$ as percent of cardiac output. $\mathrm{CBF}$ was calculated as fraction of pump flow under different flow conditions. At baseline, fractional flow to the brain was $6.5 \% \pm 1.8 \%(\mathrm{n}=8)$. During ACP, fractional flow to the brain was approximately 2 times that of baseline at all ACP flow rates (ACP-10, 14\% $\pm 6 \%, P=.006, \mathrm{n}=9$; ACP-30, 13\% $\pm 3 \%, P=.02$, $\mathrm{n}=9 ;$ ACP-50, $13 \% \pm 5 \% ; P=.01, \mathrm{n}=9$ ). ACP, Antegrade cerebral perfusion; $C B F$, cerebral blood flow.

$P=.60$; and ACP-50, $P=.96$ ). Similarly, there were no differences between left and right cerebral hemisphere $\mathrm{rSO} 2$ values at any of the measured flow rates (Figure $5, B$ : baseline, $P=.85$; ACP-10, $P=.36$; ACP-30, $P=.64$; ACP-50, $P=.63)$.

\section{DISCUSSION}

The purpose of the present study was to determine the optimal ACP flow rate under deep hypothermic CPB. We compared the $\mathrm{CBF}$ at 3 different ACP rates with that at a standard CPB total body flow rate of $100 \mathrm{~mL} / \mathrm{kg} / \mathrm{min}$.
$\%$ cerebral oxygen extraction: (CaO2 - CvO2) / $\mathrm{CaO} 2 \times 100$

$\mathrm{CaO} 2$ : arterial oxygen content, $\mathrm{CvO2:} \mathrm{jugular} \mathrm{venous} \mathrm{oxygen} \mathrm{content}$

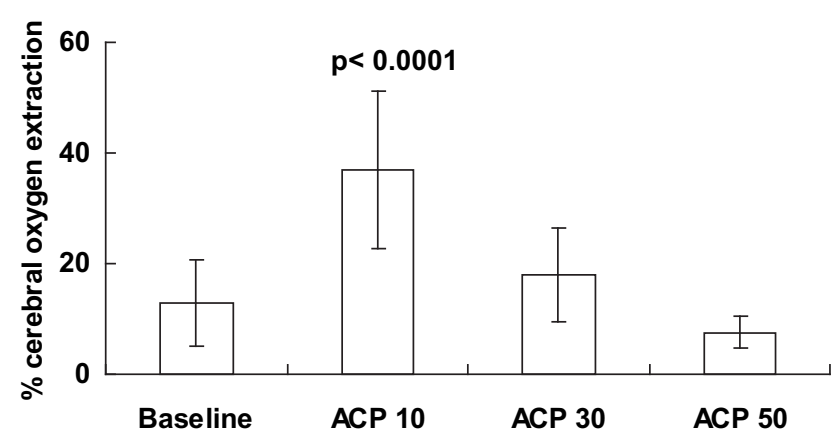

FIGURE 3. Cerebral oxygen extraction during ACP. Cerebral oxygen extraction was approximately 3 times higher at an ACP rate of $10 \mathrm{~mL} / \mathrm{kg} /$ min than that of baseline $(37 \pm 14 \% P<.0001, \mathrm{n}=8$, vs baseline $13 \pm 8$, $\mathrm{n}=8$ ). However, at an ACP rate of 30 or $50 \mathrm{~mL} / \mathrm{kg} / \mathrm{min}$, it was not different from baseline $(18 \pm 9 \%, P=.53, \mathrm{n}=9 ; 8 \pm 3 \%, P=.48, \mathrm{n}=9) . A C P$, Antegrade cerebral perfusion.

We chose the $100 \mathrm{~mL} / \mathrm{kg} / \mathrm{min}$ standard CPB condition as the baseline because it is a flow rate that is uniformly accepted as meeting metabolic demand during $\mathrm{CPB}$ at $18^{\circ} \mathrm{C}$. We fully acknowledge that opinions may differ on this value, because some consider lower flows as safe at these temperatures. This baseline was selected as a reference point for the study and understanding of ACP. Our data showed that $\mathrm{CBF}$ increased with $\mathrm{ACP}$ rate. $\mathrm{CBF}$ at an $\mathrm{ACP}$ rate of

rSO2 (NIRS)

Cranial oxygen saturation: (Right SO2 + Left SO2)/2

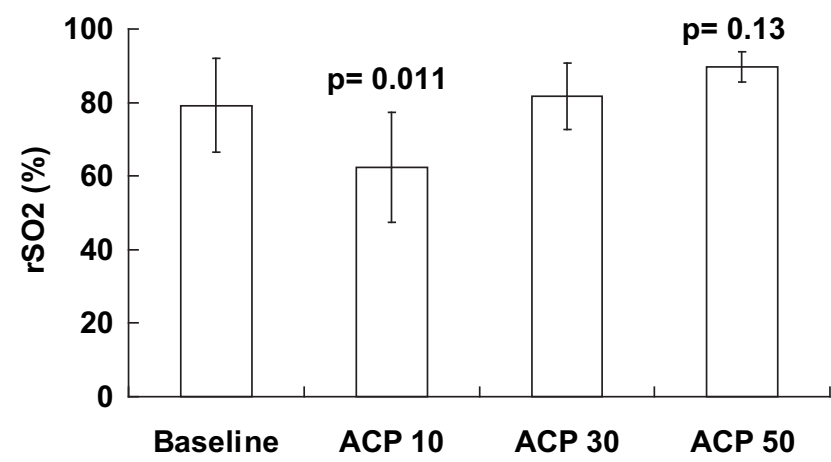

FIGURE 4. Cranial oxygen saturation during ACP. Blood distribution between right and left hemispheres was evaluated by NIRS. The average cerebral oxygen saturation of right and left hemispheres was calculated, and baseline total body flow $(79 \% \pm 13 \%, \mathrm{n}=8)$ was compared with $\mathrm{rSO} 2$ under ACP conditions. It was lower at an ACP rate of $10 \mathrm{~mL} / \mathrm{kg} / \mathrm{min}(62 \pm 15$, $P<.011, \mathrm{n}=8)$ but equal to baseline at ACP rates of $30 \mathrm{~mL} / \mathrm{kg} / \mathrm{min}(82 \pm$ $9, P=.93, \mathrm{n}=9)$ and $50 \mathrm{~mL} / \mathrm{kg} / \mathrm{min}(P=.13, \mathrm{n}=9) . r S O 2$, Regional ox ygen saturation; NIRS, near-infrared spectroscopy; $A C P$, antegrade cerebral perfusion. 


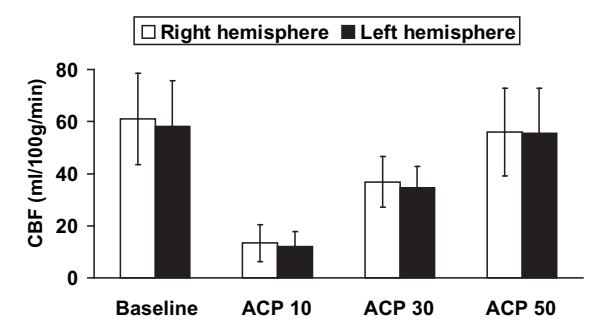

A

Blood distribution (microsphere)

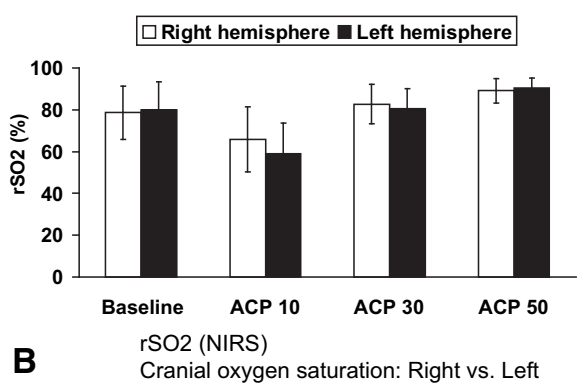

FIGURE 5. Comparison of blood flow and oxygen distribution to right and left brain hemispheres. CBF distribution to left and right brain hemispheres was measured during baseline total body flow and ACP at 3 flow rates. There was no difference in CBF to left and right sides of the brain during baseline total body flow or any of the ACP flow rates (A, baseline, $P=.75$; ACP-10, $P=.67$; ACP-30, $P=.60$, and ACP-50, $P=.96$ ). We also compared rSO2 in right and left cerebral hemispheres at different blood flow rates. We found that there were no differences between left and right cerebral hemisphere rSO2 values at baseline total body flow or any of the ACP flow rates (B, baseline, $P=.85$; ACP-10, $P=.36$; ACP-30, $P=.64$; ACP-50 $P=.63$ ). $C B F$, Cerebral blood flow; $A C P$, antegrade cerebral perfusion; $r \mathrm{SO}$, regional oxygen saturation; NIRS, near-infrared spectroscopy.

$50 \mathrm{~mL} / \mathrm{kg} / \mathrm{min}$ was equal to $\mathrm{CBF}$ at baseline total body flow, and $\mathrm{CBF}$ at an $\mathrm{ACP}$ rate of $30 \mathrm{~mL} / \mathrm{kg} / \mathrm{min}$ was approximately $60 \%$ of baseline CBF. However, $\mathrm{rSO} 2$ and cerebral oxygen extraction data revealed that an ACP rate of $30 \mathrm{~mL} /$ $\mathrm{kg} / \mathrm{min}$ could provide sufficient oxygen compared with baseline. Under deep hypothermia $\left(18^{\circ} \mathrm{C}\right)$, cerebral vascular autoregulation is not present. ${ }^{8}$ In our experiments, CBF increased linearly with ACP rate and cerebral perfusion pressure, confirming that autoregulation is not operative during ACP at these temperatures (Figure 2).

The anatomy of neck and intracranial vessels in pigs is different from that of humans. In pigs, the innominate artery gives rise to both carotid arteries and to the right subclavian artery. Despite these anatomic differences, in our pig model, the direction of blood flow (right to left) during ACP was similar to that of humans. In our experiments, we cannulated and perfused the innominate artery and clamped the left carotid artery and the left subclavian artery to initiate ACP. Isolated $\mathrm{CBF}$ was provided by the right carotid artery and right vertebral artery (by way of the right subclavian artery). The left cerebral hemisphere is perfused via the Circle of Willis, as in humans.

Distribution of systemic blood flow during CPB was reported in $1973 .{ }^{9}$ In this study, microspheres were injected into monkeys at a flow rate of 200 to $250 \mathrm{~mL} / \mathrm{kg} / \mathrm{min}$ under normothermia. The mean percentage of total systemic blood flow to the brain was approximately $10 \%$. Another group ${ }^{10}$ reported the blood distribution under normal conditions. The distribution to the brain was $11 \%$ of cardiac output in human adults, $2.6 \%$ in dogs, and $4 \%$ in newborn lambs. Our study showed that fractional flow to the brain was $6.5 \%$ under conditions of CPB at total body flow rate of $100 \mathrm{~mL} / \mathrm{kg} /$ min at $18^{\circ} \mathrm{C}$, a value well within the range expected from previously reported findings. Under all 3 ACP flow rates studied, fractional flow to the brain was approximately $13 \%$ of pump output (Figure 2, C). This increase in percentage of pump flow rate to the brain is to be expected because we are isolating flow to the upper body only during ACP.
From another perspective, however, the observation that only $13 \%$ of flow goes to the brain during ACP presents many opportunities to investigate and understand the destination of the majority of the pump flow (87\%) during ACP.

Measurement of rSO2 by NIRS has played an important role in the elucidation of the impact of congenital heart surgery on cerebral hemodynamics. ${ }^{11}$ Measurement of $\mathrm{rSO} 2$ using NIRS devices indicates regional oxygen metabolism and the balance of local tissue oxygen supply versus demand. Daubeney and colleagues ${ }^{12}$ reported a close correlation between cerebral regional oxyhemoglobin saturation measured by NIRS and jugular bulb saturation $(r=0.69$, $P<.0001)$ in 40 children undergoing cardiac catheterization or cardiac surgery. Our data also revealed that cerebral oxygen extraction was inversely proportional to the NIRS values and that $\mathrm{CBF}$ was directly related to $\mathrm{rSO} 2$.

\section{CONCLUSIONS}

$\mathrm{CBF}$ increases with $\mathrm{ACP}$ flow at $18^{\circ} \mathrm{C}$, and there are no left/right hemisphere imbalances even under very low ACP flows. Compared with our chosen baseline flow of $100 \mathrm{~mL} / \mathrm{kg} / \mathrm{min}$ under conditions of standard $\mathrm{CPB}$, an ACP rate of $30 \mathrm{~mL} / \mathrm{kg} / \mathrm{min}$ provides approximately $60 \%$ of baseline $\mathrm{CBF}$, but rSO2 and cerebral oxygen extraction are equal to the baseline data, suggesting equal oxygenation in the brain. On the other hand, an ACP rate of $50 \mathrm{~mL} / \mathrm{kg} /$ min provides $\mathrm{CBF}$ equal to baseline, but $\mathrm{rSO} 2$ trended higher than baseline and cerebral oxygen extraction trended lower than baseline, suggesting more oxygenation in the brain. This suggests that higher ACP rates in the "clinically acceptable" range may provide excessive blood flow to the brain and potentially have a deleterious effect, including endothelial damage. DeCampli and colleagues ${ }^{13}$ reported that regional low-flow perfusion at a higher flow rate was associated with upper torso edema, greater post-CPB acidosis, and an overall declining clinical course after CPB. Further studies should focus on these concerns. In addition, some surgeons are now using $\mathrm{ACP}$ at temperatures of $25^{\circ} \mathrm{C}$ or 
$28^{\circ} \mathrm{C}$, a condition under which the brain oxygen demand also increases. A higher ACP flow rate may be needed to provide sufficient blood flow to the brain at higher ACP temperatures. An understanding of the flow characteristics of ACP methodology under moderate and mild hypothermia, including the influence of vascular autoregulation, is needed.

\section{References}

1. Pigula FA, Nemoto EM, Griffith BP, Siewers RD. Regional low-flow perfusion provides cerebral circulatory support during neonatal aortic arch reconstruction. J Thorac Cardiovasc Surg. 2000;119:331-9.

2. Andropoulos DB, Stayer SA, McKenzie ED, Fraser CD Jr. Novel cerebral physiologic monitoring to guide low-flow cerebral perfusion during neonatal aortic arch reconstruction. J Thorac Cardiovasc Surg. 2003;125:491-9.

3. Goldberg CS, Bove EL, Devaney EJ, Mollen E, Schwartz E, Tindall S, et al. A randomized clinical trial of regional cerebral perfusion versus deep hypothermic circulatory arrest: outcomes for infants with functional single ventricle. $J$ Thorac Cardiovasc Surg. 2007; 133:880-7.

4. Visconti KJ, Rimmer D, Gauvreau K, del Nido P, Mayer JE Jr, Hagino I, et al. Regional low-flow perfusion versus circulatory arrest in neonates: one-year neurodevelopmental outcome. Ann Thorac Surg. 2006;82:2207-13.

5. Rastan AJ, Walther T, Alam NA, Daehnert I, Borger MA, Mohr FW, et al. Moderate versus deep hypothermia for the arterial switch operation- experiences with 100 consecutive patients. Eur J Cardiothorac Surg. 2008;33:619-25.

6. Klaessens JH, Hopman JC, Liem KD, van Os SH, Thijssen JM. Effects of skin on bias and reproducibility of near-infrared spectroscopy measurement of cerebral oxygenation changes in porcine brain. J Biomed Opt. 2005;10:44003.

7. Heymann MA, Payne BD, Hoffman JI, Rudolph AM. Blood flow measurements with radionuclide-labeled particles. Prog Cardiovasc Dis. 1977;20:55-79.

8. Greeley WJ, Ungerleider RM, Smith LR, Reves JG. The effects of deep hypothermic cardiopulmonary bypass and total circulatory arrest on cerebral blood flow in infants and children. J Thorac Cardiovasc Surg. 1989;97:737-45.

9. Rudy LW Jr, Heymann MA, Edmunds LH Jr. Distribution of systemic blood flow during cardiopulmonary bypass. J Appl Physiol. 1973;34:194-200.

10. Hales JR. Radioactive microsphere measurement of cardiac output and regional tissue blood flow in the sheep. Pflugers Arch. 1973;344:119-32.

11. Chakravarti S, Srivastava S, Mittnacht AJ. Near infrared spectroscopy (NIRS) in children. Semin Cardiothorac Vasc Anesth. 2008;12:70-9.

12. Daubeney PE, Pilkington SN, Janke E, Charlton GA, Smith DC, Webber SA. Cerebral oxygenation measured by near-infrared spectroscopy: comparison with jugular bulb oximetry. Ann Thorac Surg. 1996;61:930-4.

13. DeCampli WM, Schears G, Myung R, Schults S, Creed J, Pastuszko A, et al. Tissue oxygen tension during regional low-flow perfusion in neonates. J Thorac Cardiovasc Surg. 2003;125:472-80.

\section{Discussion}

Dr Randall Griepp (New York, NY). I have no financial disclosures. Dr Sasaki, I congratulate you and your colleagues on addressing the issue of optimizing perfusion during pediatric cardiac surgery. I have a number of comments, criticisms, and questions, but I do have a soft spot for my colleagues from my former alma mater, so I will be as tactful as possible.

In optimizing perfusion, what we are really looking at is cerebral protection and survival of the animals with normal neurologic func- tion. Why not develop a survival model, wake the animals up and make sure that you haven't injured them?

Dr Sasaki. In this study our main focus was comparing blood flow under conditions of ACP with that under standard CPB. The relationship between the 2 bypass techniques has never been established. We didn't choose a survival model for this study, but in the future we plan to do so to investigate cerebral histology after ACP.

Dr Griepp. The cerebral metabolic rate for oxygen is affected by the $\mathrm{pH}$ of the perfusate and whether you use selective cerebral perfusion or CPB. Why not cannulate the sagittal sinus so you can get a reasonable estimate of mixed venous saturation from the brain, and then you can calculate CMR02 and determine whether CMR02 is changing under the circumstances of your experiment?

Dr Sasaki. We agree that we may see more accurate values from sagittal sinus sampling. But in our piglet models we use very small animals $(3-4 \mathrm{~kg})$, so the available area is very small and there is limited space for multiple monitoring devices. We were primarily interested in bilateral NIRS monitoring for this study, so we didn't collect the samples from the sagittal sinus. Instead, we collected venous samples from the left jugular vein and calculated oxygen metabolism.

Dr Griepp. Okay, but it's troubling to hear pediatric surgeons say that the blood vessels are too small to work with. The final question has to do with the issue of autoregulation and $\mathrm{pH}$ of the perfusion. There is reasonably good experimental evidence that use of $\mathrm{pH}$-stat when cooling animals in preparation for hypothermic circulatory arrest improves cooling, and there's some clinical evidence to suggest that $\mathrm{pH}$-stat under those circumstances is preferable. However, under the circumstances of continuous selective cerebral perfusion, I do not believe there is any experimental evidence, or any clinical evidence, that $\mathrm{pH}$-stat is preferable. We have shown in a similar model that $\mathrm{pH}$-stat and alpha-stat differ profoundly, and the $\mathrm{pH}$-stat clearly destroys autoregulation at these temperatures. The excessive cerebral flow increases intracranial pressure and cerebral metabolic rate for oxygen and undoubtedly increases the potential for microemboli because the flow is much greater than that needed for oxygen delivery. Why use $\mathrm{pH}$-stat continuous selective cerebral perfusion? Why not use alpha-stat under these circumstances?

Dr Sasaki. We followed our institutional protocol, which precluded survival for these studies. Our surgeons use $\mathrm{pH}$-stat during cooling, so we'd like to reproduce the clinical situation as much as possible in the piglet model. As you mentioned, it's still a controversial problem regarding optimal blood gas management during selective cerebral perfusion, so I think I also need to do another kind of experiment focusing on optimal blood gas management in the next step. In this study, we manipulated a number of variables and anticipate exploring alpha-stat in the future.

Dr Griepp. Once again, I congratulate you and your colleagues for approaching these important but difficult questions. 